\title{
COMPETITION IN TOURISM ARRIVALS: A MULTIDIMENSIONAL INDEX OF GEOGRAPHICAL STRUCTURAL SIMILARITY
}

\author{
NUNO CRESPO, NÁDIA NOGUEIRA SIMÕES, AND JOSE MARIA DUARTE
}

ISCTE Business School Economics Department, Instituto Universitário de Lisboa (ISCTE-IUL), Lisbon, Portugal

\begin{abstract}
Given the economic importance of the tourism sector, countries actively compete for attracting tourism flows. In a bilateral perspective, an important determinant of the degree of competition is the geographical structure of tourism inflows (i.e., the relative importance of the different source countries). A higher overlap of these flows indicates greater competition. The present study proposes a methodological approach to quantify this overlap. Taking some indicators traditionally used in international trade analysis as inspiration, we propose a methodology that measures, for each pair of countries, the degree of similarity between the geographical structures of tourism inflows. The methodology takes a multidimensional concept of structural similarity in order to incorporate relevant dimensions of international tourism flows today.
\end{abstract}

Key words: Tourism flows; Arrivals; Geographical similarity; Competitiveness; Index

\section{Introduction}

The tourism industry is widely recognized as a crucial element in the development strategies of the countries (European Commission, 2007). Tourism activities have considerable economic effects. As surveyed by Sinclair (1998), they contribute to economic growth and job creation, they improve the balance of payments, increase household incomes and government revenues, generate important multiplier effects in other sectors, and may cause an increase of trade. ${ }^{1}$ Because of this, countries compete intensively, seeking to increase their market shares of world tourism. In this context, two aspects should be highlighted. First, despite the fact that distance is still an important determinant of international tourism flows (McKercher, Chan, \& Lam, 2008; McKercher \& Lew, 2003), there is a trend toward globalization of tourism. This trend is driven by, among other things, falling transportation costs and the rise of emerging countries as important sources of tourists. Second, heterogeneous demand for tourism services has led to segmentation as a critical dimension of the marketing strategy.

At the level of the different countries (and regions), we now see the emergence of strategic 
planning for the development of the tourism sector (Kirovska, 2011; Lusticky, 2011). This strategy naturally involves the strengthening of their competitive conditions as emphasized in the literature on tourism destination competitiveness (Crouch, 2007; Dwyer \& Kim, 2003; Mazanec \& Ring, 2011; Mazanec, Wöber, \& Zins, 2007; Ritchie \& Crouch, 2003).

Although the dominant approaches to evaluate the competition among countries to attract tourism flows focus on the supply conditions, namely the most important competitiveness determinants, our perspective highlights the demand side, looking at an underexplored feature: the geographical structural similarity (GSS) of tourism demand. This is an important aspect because tourism flows for specific destination markets are also strongly influenced by the characterization elements of the source countries. Moreover, considering the most commonly applied approach together with the methodology developed in this study might lead to a richer understanding of the complex network of tourism flows at the international level as well as of the actual and future economic implications for countries that, in some cases, put this sector at the center of their growth and development strategy.

Specifically, our main contribution is to propose a method to quantify the degree of geographical structural similarity that includes the several features that are relevant for its correct and quantified evaluation. With that objective, we take as inspiration the indices traditionally used in international trade analysis to evaluate the degree of competition between two countries in a specific market, but provide a new conceptual framework that allows incorporating the additional complexity and the new dimensions that are specific to the evaluation of tourism flows. Measuring the GSS between pairs of countries gives us information on the competition between these countries as tourism destinations. Additionally, the development of a multidimensional approach such as the one we propose in this study allows us to identify in greater detail the causes behind the levels of competition calculated.

The remainder of the article is organized as follows. In the next section we provide a literature review on tourism destination competitiveness and present the standard measure of structural similarity. In the third section we develop a methodology to assess geographical structural similarity in terms of tourism flows. The methodology proposed is illustrated in the fourth section. In the last section, conclusions are presented.

\section{Theoretical Background}

\section{Tourism Destination Competitiveness}

Tourism destination competitiveness is a research topic of growing interest not only among tourism researchers but also for policy makers and practitioners. Therefore, the emergence of several research strands on this topic is not surprising. A first group of studies focuses on specific dimensions of destination competitiveness, including destination management systems, destination marketing, quality management, environment, nature-based tourism, and strategic management (Crouch, 2007). There are also some studies focusing on price competitiveness, which can be seen as a first and simpler interpretation of the competitiveness concept (Mazanec et al., 2007). Dwyer, Forsyth, and Rao $(2000,2002)$ are examples of important studies on this topic. In their turn, Dwyer and Forsyth (2010) provide an important contribution to this literature, discussing the importance of destination price competitiveness and analyzing their determinants and measures in detail.

A second strand of the literature seeks to evaluate the competitive positions of specific destinations, including the cases of Australia and Korea (Kim \& Dwyer, 2003), Spain and Turkey (Kozak, 2002), Hong Kong (Enright \& Newton, 2004), Asia-Pacific (Enright \& Newton, 2005), Slovenia (Gomezelj \& Mihalic, 2008), and Southern Italian regions (Cracolici \& Nijkamp, 2009), among others.

Finally, a third research avenue develops general models and theories of destination competitiveness (Crouch, 2007). The most important contribution in this area is, without doubt, the model(s) proposed by Ritchie and Crouch in several studies (Crouch \& Ritchie, 1999; Ritchie \& Crouch, 2000, 2003). Their main goal is to consider all of the important factors that characterize tourism competitiveness of a destination. This is concretized through the development of a conceptual framework that simultaneously includes critical elements of the comparative advantage and competitive advantage theories. In fact, this approach assumes that 
destination competitiveness depends not only on the destination's resource endowments (i.e., comparative advantage), but also on its capacity to deploy resources (i.e., competitive advantage).

Additionally, the model recognizes the importance of global macroenvironmental forces (including, for instance, the evolution of the global economy, demographic trends, and terrorism) as well as competitive microenvironmental elements affecting the tourism system. In the most recent versions of this model, destination competitiveness is determined by five groups of factors: core resources and attractors, supporting factors and resources, destination management, destination policy, and qualifying and amplifying determinants. In total, 36 destination attributes are included. Despite its importance and wide application, this model has some limitations, such as the fact that some indices proposed by the authors cannot be calculated and the exclusion of ecoenvironmental quality (Zhang, $\mathrm{Gu}, \mathrm{Gu}$, \& Zhang, 2011).

Similar to this model of Ritchie and Crouch (2000, 2003), the study of Dwyer and Kim (2003) proposes a holistic approach of determinants and indicators that define destination competitiveness (Mazanec et al., 2007). The indicators proposed are grouped in the following subgroups: endowed resources, supporting factors, destination management, situational conditions, demand factors, and market performance indicators. In a related study, Dwyer, Mellor, Livaic, Edwards, and Kim (2004) factorized 83 competitiveness indicators discussed in Dwyer and Kim (2003), obtaining 12 principal components.

An important and recent contribution for measuring destination competitiveness is provided by the Travel \& Tourism Competitiveness Report, published by the World Economic Forum (2013). Beginning in 2007, this report presents the Travel and Tourism Competitiveness Index (TTCI), which, in an effort to evaluate the competitiveness of each country regarding the travel and tourism industry, considers 14 pillars of competitiveness, namely: policy rules and regulation, environmental sustainability, safety and security, health and hygiene, prioritization of travel and tourism, air transport infrastructure, ground transport infrastructure, tourism infrastructure, ICT infrastructure, price competitiveness in the industry of travel and tourism, human resources, affinity for travel and tourism, natural resources, and cultural resources. Based on these pillars, three subindices are obtained: the Travel and Tourism (T\&T) regulatory framework index, the T\&T business environment and infrastructure index, and the T\&T human, cultural, and natural resources index.

This approach is not immune to criticism. In fact, several authors stress important methodological limitations concerning the lack of a theoretical support for several of the variables included, the statistical methods used to demonstrate the usefulness of the index, the simultaneous inclusion of countries with different development levels, the weights of the variables, and the combining of hard data with survey data, among other aspects (Mazanec \& Ring, 2011; Mazanec et al., 2007; Squalli, Wilson, \& Hugo, 2008). Hall (2007) presents a more substantive criticism to the mainstream approach of destination competitiveness, emphasizing that some weaknesses emerge when, at conceptual level, destination competitiveness is analyzed in the same way as firm competitiveness (on this topic, see also Bristow, 2005).

\section{A Standard Measure of Structural Similarity}

Given the important economic impacts of the tourism sector, the countries compete fiercely to attract tourists. They do this by reinforcing their competitive conditions, namely by improving their resource endowments and creating differentiation vis-à-vis other destinations. Developing more aggressive and differentiated marketing strategies is also important in promoting the destination countries. This has been recognized for instance by Kulendran and Dwyer (2009), Zhang, Kulendran, and Song (2010), and Song, Dwyer, Li, and Cao (2012), despite the fact that, in general terms, marketing elasticities are low (Song et al., 2012).

However, competition between countries depends not only on their supply conditions but also on the geographical structure of demand. Obviously, these two perspectives are linked, because tourism demand depends critically on the characteristics of the supply. In this study, we seek to develop a new approach that focuses on the degree of GSS between the countries, that is, which analyzes and quantifies the level of proximity between the structures of tourism flows going to the two countries in terms of source countries. 
The methodology proposed in this study is inspired by an approach commonly used in international trade analysis. As applied there, the purpose is to assess the degree of competition between two export structures for a given market (Crespo \& Fontoura, 2007; De Benedictis \& Tajoli, 2007; Palan \& Schmideberg, 2010; among many others). Such analyses consider measures such as the FingerKreinin, the Gini, the Krugman, and the HerfindahlHirschman indices (Palan, 2010). The most frequently applied of these measures - the Krugman index - evaluates the degree of similarity between the export structures of a given pair of countries in order to assess the level of trade competition between them. To do so, the index compares the weight of each sector in total exports for both countries toward a given destination market. It can be expressed as:

$$
K R_{12}=\sum_{q=1}^{Q}\left|\frac{\operatorname{Exp}_{1 q}}{\sum_{q=1}^{Q} \operatorname{Exp}_{1 q}}-\frac{\operatorname{Exp}_{2 q}}{\sum_{q=1}^{Q} \operatorname{Exp}_{2 q}}\right|
$$

In which $K R_{12}$ represents the Krugman index between countries 1 and 2, with $\operatorname{Exp}_{1 q}$ and $\operatorname{Exp}_{2 q}$ being the exports of sector $q$ by country 1 and 2, respectively. Export similarity will be maximumindicating the highest level of competition-when the share of each sector $q$ is exactly the same in the export structures of both countries, that is, when for

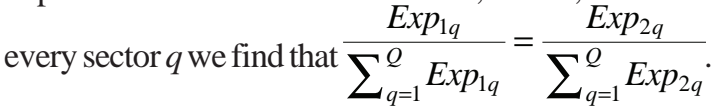
In such a case, $K R_{12}$ assumes the value 0 . In its turn, when the dissimilarity is maximum, the Krugman index takes the value 2, indicating the lowest level of trade competition.

Based on this kind of measure, several studies analyze the level of trade competition between two or more countries in a given destination market. For example, associated with the enlargement process of the EU in 2004 (with the accession of 10 new member states), several articles (including some of the above mentioned) investigated the implications of this liberalization process for the previous members. The Krugman index gives us a quantitative measure of the level of trade competition between the new and the old members in the European market.

Recently, Crespo and Simões (2012) propose two extensions to this standard measure, incorporating in a single index, three dimensions of structural similarity: the sectoral weights (as in the Krugman index), the intersectoral similarity, and the intrasectoral similarity. The concept of intersectoral similarity takes into consideration how different the distinct sectors are and intrasectoral similarity does the same concerning the degree of similarity in terms of quality ranges exported.

In the next section we describe the methodology used in the present study. Our starting point is a modified (and richer) version of the Krugman index that not only incorporates the extensions suggested for trade analysis by Crespo and Simões (2012), but also allows us to address the several specificities of measuring geographical structural similarity in tourism flows. The most important of these specificities is related to a particular but crucial issue: when we compare the export or import composition of two countries we know that the range of products they can potentially trade is exactly the same. Nevertheless, in tourism this is not the case. Each destination country has a list of source countries that is different from the one we define for another country. For example, if we take France as destination market, the potential source countries do not include this country, while for Spain, France is on this list. This issue should not be perceived as a limitation but instead as a characteristic of tourism flows that calls for new approaches that are able to take the existing ones as starting point and make the necessary adaptations to study this phenomenon. This is the main objective of the present study.

\section{Methodology}

\section{The Base Index}

Preliminary Considerations. The method proposed in this study adapts and extends the approach presented in the previous section. However, the application of such indicators to the analysis of tourism flows is not direct and requires a new conceptual framework. Two adaptations are especially noteworthy. First, a detailed analysis of the degree of GSS demands the consideration of new dimensions that are specific to the analysis of tourism flows (including, for instance, different forms of segmentation), leading to a multidimensional and 
more complex concept of GSS. Second, the fact that, given the nature of our study, we perform the evaluation of geographic similarity instead of sectoral similarity (as in the case of trade analysis) creates an additional level of complexity at the methodological level. The main problem in this regard is, as we explained above, the fact that while in the case of sectoral similarity all the countries export the same products, in the evaluation of GSS, the group of source countries is different for every country, requiring the adaptation of the measures.

The index of similarity that we propose allows us to compare the structures of tourism inflows between two countries, $f$ and $g$. The index $h(h=1$, $2, \ldots, H)$ expresses the source country of the tourism flows (excluding $f$ and $g$ ). Therefore, $A_{f h}$ and $A_{g h}$ represent the flows of tourists from $h$ to $f$ and $g$, respectively. In turn, $A_{f g}$ expresses the flow of tourists from $g$ to $f$, while $A_{g f}$ represents the flow of tourists from $f$ to $g$. Therefore, the total volume of tourism inflows into country $f$ is given by the sum of tourism flows from each country $h$ to $f$ and the flow from $g$ to $f$ :

$$
A_{f}=\sum_{h=1}^{H} A_{f h}+A_{f g} \text {. }
$$

The same definition applies to country $g$, and therefore the total volume of tourism inflows into $g$ is expressed as:

$$
A_{g}=\sum_{h=1}^{H} A_{g h}+A_{g f} \text {. }
$$

Aiming to build, below, the GSS index, we must also take into consideration the importance of the bilateral tourism flows between the countries that are being evaluated ( $f$ and $g$ ). To this end we begin by defining, for each of these countries, the weight of the flow of tourists that come from the other country as a proportion of total arrivals. For example, the weight of source country $g$ in total tourism flows that arrive at $f$ is given by:

$$
X_{f g}=\frac{A_{f g}}{A_{f}} .
$$

In turn, the weight of source country $f$ in total tourism flows arriving at $g$ is:

$$
X_{g f}=\frac{A_{g f}}{A_{g}} .
$$

Finally, the average of these values-which will be used below for the construction of our GSS measures-is given by:

$$
X_{f g}^{\prime}=\frac{X_{f g}+X_{g f}}{2} .
$$

An Index of Geographical Structural Similarity. In order to measure the degree of GSS between the tourism flows arriving at $f$ and $g$, we calculate the following index:

$$
M_{f g}=1-\beta\left[\sum_{h=1}^{H}\left|\theta_{f h}-\theta_{g h}\right|\right]
$$

in which:

$$
\theta_{f h}=\frac{A_{f h}}{\sum_{h=1}^{H} A_{f h}}
$$

and

$$
\theta_{g h}=\frac{A_{g h}}{\sum_{h=1}^{H} A_{g h}} .
$$

As is clear from equation (7), $M_{f g}$ directly compares the relative weight of each source country in the tourism that goes to $f$ and $g$. When compared with the Krugman index [equation (1)] this measure has two differences. The first is the consideration of a parameter $\beta$ in order to adjust the valid range of $M_{f g}$. Hereinafter, following the usual procedure in trade literature, we assume that $\beta=1 / 2$. The objective is to make the interpretation easier because the admissible range for the Krugman index$[0,2]$ - is not intuitive. With $\beta=1 / 2, M_{f g}$ ranges in the more "comfortable" $[0,1]$ interval. Second, despite being a measure of structural similarity, the Krugman index increases with structural dissimilarity. In order to overcome this problem, we consider as our GSS measure a modified version in which the maximum value $\left(M_{f g}=1\right)$ occurs when there is a perfect similarity in the geographical structure of tourism flows that go to $f$ and $g$, that is, the case in which each source country has exactly the same weight in the structures of the two countries. For its part, $M_{f g}=0$ when there is a perfect dissimilarity between these structures, which occurs when the source countries of the tourism flows that go to $f$ are different from those that go to $g$. Although his case expresses the minimum level of competition between $f$ and $g$, a higher value of $M_{f g}$ indicates 
a stronger potential competition between the two countries because, in that case, $f$ and $g$ depend, in more similar proportions, on the same countries as sources of tourism flows.

However, $M_{f g}$ compares only the geographical structure of tourism flows coming from the various countries $h$. In order to have a complete index that also considers the influence of the bilateral flows between $f$ and $g$, we introduce the following correction:

$$
M_{f g}^{\prime}=\left(1-X_{f g}^{\prime}\right) M_{f g}+X_{f g}^{\prime}\left(1-\left|X_{f g}-X_{g f}\right|\right) .
$$

In order to illustrate the logic behind the construction of this measure, let us consider a simple example with $X_{f g}=0.1$ and $X_{g f}=0.2$. In this case, $X_{f g}^{\prime}=0.15$ and therefore $M_{f g}^{\prime}=0.85 M_{f g}+0.15 \times 0.9$. This index-our base measure-reaches the value 1 , representing maximum GSS, when, in addition to the structural similarity in the flows from countries $h, X_{f g}=X_{g f}$.

\section{Other Dimensions}

In the previous section, we proposed a GSS index that measures the degree of overlap between the geographical structures of tourism arriving at $f$ and $g$. However, this indicator considers only the relative weights of the different source countries. In this section we argue that a more detailed analysis of the degree of structural similarity requires that other dimensions be taken into account. We consider four additional dimensions (volume of tourism, groups of countries, and two forms of market segmentation - trip motivation and types of tourists), allowing us to qualify the results obtained from $M_{f g}^{\prime}$. These new dimensions will first be included on an individual basis. Following, we will propose a measure that aggregates all of them.

The Volume of Tourism. The first new dimension considered is the volume of tourism. As suggested by Jenkins (2008) in the context of trade literature, the level of competition between two countries with regard to tourism inflows will be higher when the total number of tourists arriving in the two countries is similar than in the case where there is a large discrepancy in these flows, even if the geographical structure is exactly the same. To measure the level of overlap between the total volumes of tourism in the two countries, we calculate:

$$
\psi_{f g}=\frac{\operatorname{Min}\left(\sum_{h=1}^{H} A_{f h}, \sum_{h=1}^{H} A_{g h}\right)}{\operatorname{Max}\left(\sum_{h=1}^{H} A_{f h}, \sum_{h=1}^{H} A_{g h}\right)} .
$$

To adjust $M_{f g}$ in order to include both the geographical structure of tourism flows going to $f$ and $g$ and the level of overlap between the volumes of these flows, we obtain:

$$
V_{f g}=M_{f g}-\frac{1}{\tau}\left(1-\psi_{f g}\right) M_{f g} .
$$

As can be seen, compared with $M_{f g}$, the index $V_{f g}$ corrects the level of similarity between the two distributions according to the degree of overlap of the total volume of tourism inflows arriving at $f$ and $g$. The parameter $\tau(\tau \geq 1)$ works as an adjustment factor, in which higher values reflect a lower importance attributed to this dimension of structural similarity, translated into a smaller adjustment to $M_{f g}$. To illustrate this aspect, consider for example the case in which $M_{f g}=0.7$ and $\psi_{f g}=0.87$. When we assume $\tau=1$ the value for $V_{f g}$ is $0.7-(1-0.87) \times$ $0.7=0.609$; but when $\tau=2$ we obtain $V_{f g}$ equal to $0.7-0.5 \times(1-0.87) \times 0.7=0.655$.

The index of structural similarity that considers this dimension, aside from the weights of the source countries, can then be expressed as:

$$
V_{f g}^{\prime}=\left(1-X_{f g}^{\prime}\right) V_{f g}+X_{f g}^{\prime}\left(1-\left|X_{f g}-X_{g f}\right|\right)
$$

In this case, the maximum similarity between the structures of the tourism flows arriving at $f$ and $g$ requires: (1) structural similarity concerning the tourism flows from countries $h$ to $f$ and $g$, (2) equality between the total volumes of tourism associated with these flows, and (3) $X_{f g}=X_{g f}$.

Groups of Countries. The GSS index proposed above treats all countries equally and does not incorporate any distinction between countries that, in light of a given criterion, belong or do not belong to a more homogeneous group. However, in terms of competition analysis, it seems desirable to differentiate between groups of countries. In our context of analysis, two criteria seem to be especially relevant: the development level of the countries (for 
example, following the United Nations classification; see United Nations Development Programme, 2011) or their geographic location (e.g., groups of geographically close countries, continents, etc.).

To illustrate the importance of this dimension, let us consider the geographical criterion as example. To include this dimension, we start by considering various levels of geographical separation, defined by the index $j(j=1, \ldots, J)$ such that, as we consider more disaggregated levels, geographical proximity between the countries of each group is higher, until we reach the final level of disaggregation, corresponding to the country level $(j=J)$.

Let us consider a case with three levels of disaggregation: continents $(j=1)$, regions $(j=2)$, and countries $(j=J=3)$. In this scenario, if we are analyzing tourism flows to Canada and Mexico from Portugal, Spain, Hungary, and Australia, all the source countries are obviously different at the most disaggregated level $(j=3)$, but different situations occur at the other levels. At the region level, Portugal and Spain would belong to the same group, while the others would be in different ones. Finally, at level 1, Portugal, Spain, and Hungary would be in the same group (Europe). In the measure that we propose below we aim to incorporate these differences.

Let us take an oversimplified example. In situation A, all the tourists arriving at Mexico come from Spain, while tourism inflows into Canada are exclusively from Portugal. In situation B, tourism to Mexico is now from Australia, while for Canada it continues to come from Portugal. In both cases, our baseline GSS index will be zero. However, we can argue that Portugal and Spain are more similar in terms of social and economic characteristics (due to their geographical proximity) than either of them in comparison to Australia. Therefore, a more complete index of GSS should indicate a higher level of (potential) competition in situation A than in situation B.

The first step in this procedure is to calculate the previously proposed index- $M_{f g}$-for each of the $J$ levels of spatial disaggregation. Thus, we have:

$$
M_{f g}^{j}=1-\frac{1}{2}\left[\sum_{h_{j}=1}^{H_{j}}\left|\theta_{f h_{j}}-\theta_{g h_{j}}\right|\right] .
$$

The second step is to obtain the weighted average of the indices calculated at the different levels of disaggregation. Thus, we calculate:

$$
B_{f g}=\sum_{j=1}^{J} \mu^{j} M_{f g}^{j}
$$

in which, obviously $\sum_{j=1}^{J} \mu^{j}=1$.

As the example above makes clear, the greater the importance assigned to this dimension, the greater should be the weight given to the indicators based on more geographically aggregated levels. The corrected index which includes this dimension is obtained as:

$$
B_{f g}^{\prime}=\left(1-X_{f g}^{\prime}\right) B_{f g}+X_{f g}^{\prime}\left(1-\left|X_{f g}-X_{g f}\right|\right) .
$$

In this case, the maximum structural similarity is achieved when: (1) whatever the level of disaggregation considered, the weight of each group of countries is exactly the same with regard to tourism inflows in $f$ and $g$, and (2) $X_{f g}=X_{g f}$. It should be noted that if $\mu^{J}>0$ the condition (1) mentioned at the end of the section dedicated to the base index is sufficient to ensure compliance with the condition (1) above.

Trip Motivation. The existence of a heterogeneous demand for tourism services, along with increasing competition in the market, has led to the development of segmentation as a fundamental feature of the marketing strategy (Bloom, 2004; Chen, 2003; Dumitrescu \& Vinerean, 2010). The goal of market segmentation is to divide the tourism demand into more homogeneous subgroups based on several characteristics such as socioeconomic factors, geographical location, and trip motivation. In fact, as emphasized by Papatheodorou (2001), "consumer heterogeneity is a stylized fact and all the efforts of marketing aim at discovering and targeting specific leisure groups" (p. 165).

Let us consider the case of trip motivation. We incorporate this dimension in our index of structural similarity, reducing the degree of GSS if tourists have different motivations for their trips, even if the source country is the same. In this case, the competition between the two countries under comparison is weaker.

We start by defining the index $t(t=1,2, \ldots, T)$ concerning the motivation of the trip, which will break down the flow from each source country in $T$ segments, leading to the consideration of HT flows (to which is added, of course, the flow coming from the other country under comparison). For the sake 
of simplicity, we exclude the case where more than one motivation is behind a given tourism flow.

A simple way to incorporate this dimension in the GSS index is to calculate the following measure:

$$
I_{f g}=1-\frac{1}{2}\left[\sum_{h=1}^{H} \sum_{t=1}^{T}\left|\theta_{f h t}-\theta_{g h t}\right|\right],
$$

where:

$$
\theta_{f h t}=\frac{A_{f h t}}{\sum_{h=1}^{H} \sum_{t=1}^{T} A_{f h t}}
$$

and

$$
\theta_{g h t}=\frac{A_{g h t}}{\sum_{h=1}^{H} \sum_{t=1}^{T} A_{g h t}} .
$$

where $\theta_{\text {fht }}$ represents the weight of tourism flows from country $h$ with the specific motivation $t$ in the total flows arriving at $f$ coming from all the source countries $h$. $\theta_{\text {ght }}$ has the same meaning for the case of destination country $g$.

The index that jointly captures the two dimensions of GSS - weights of each source country and trip motivation—could then be represented as:

$$
I_{f g}^{\prime}=\left(1-X_{f g}^{\prime}\right) I_{f g}+X_{f g}^{\prime}\left(1-\left|X_{f g}-X_{g f}\right|\right) .
$$

However, this approach is not immune to criticism. An important limitation derives from the fact that different travel motivations coming from the same country are treated in the same way as are flows from different countries. This may be considered excessive. Accordingly, we propose a simple alternative approach that consists of calculating the weighted average of the indicator with and without disaggregation by travel motivation, weighted respectively by $\kappa_{1}$ and $\kappa_{2}$. A higher value for $\kappa_{1}$ indicates greater emphasis on the motivation of the trip as a dimension of geographic structural similarity. Thus, we have:

$$
U_{f g}=\kappa_{1} I_{f g}+\kappa_{2} M_{f g}
$$

with $\kappa_{1}+\kappa_{2}=1$.h

In this case, the index that considers both dimensions is expressed as:

$$
U_{f g}^{\prime}=\left(1-X_{f g}^{\prime}\right) U_{f g}+X_{f g}^{\prime}\left(1-\left|X_{f g}-X_{g f}\right|\right) .
$$

The maximum level of GSS requires, in this case, that: (1) the relative weight of each segment $t$ coming from each country $h$ is the same in the flows that go to $f$ and $g$, and (2) $X_{f g}=X_{g f}$.

Types of Tourists. The fact that two countries capture tourists from the same country (perhaps even in the same proportion of the total number of tourists that arrive at those countries) does not imply that they are reaching the same segment in terms of, for example, purchasing power. A more detailed indicator of GSS should incorporate this distinction, indicating a higher level of similarity when the countries capture not only tourists from the same country but also from the same segment in terms of purchasing power.

This dimension shares with the previous one the fact that it involves the breakdown of the flvows from each source country. However, unlike what occurs in the previous dimension, there is now a more explicit hierarchy (i.e., a ranking of the different segments). To that extent, although direct adaptations of the two approaches applied in the previous section are also valid, in this section we seek to define more adequate approaches for this specific case.

The first step is to define the segment to which the flow from each country belongs. Considering first the case of country $f$, let us compare the level of per capita income of the tourists coming from $h$ to $f\left(Y_{f h}\right)$ with the level of per capita income of all the tourists that come out of $h\left(Y_{h}\right)$ :

$$
\lambda_{f h}=\frac{Y_{f h}}{Y_{h}} .
$$

Next, we define the different segments corresponding to different levels of average income. For simplicity, we consider three segments but the generalization to a different number of segments is immediate, being enough to define new criteria for the separation between the various segments:

$$
D_{f h}=\left\{\begin{array}{c}
1 \text { if } \lambda_{f h}>1+\gamma \\
2 \text { if } \frac{1}{1+\gamma} \leq \lambda_{f h} \leq 1+\gamma \\
3 \text { if } \lambda_{f h}<\frac{1}{1+\gamma}
\end{array}\right.
$$

where $\gamma(\gamma>0)$ is a parameter that allows us to establish the separation between the three segments 
considered: $D_{f h}=1$ corresponds to the high income per capita segment, $D_{f h}=2$ for medium level, and $D_{f h}=3$ for the lower level. If, for example, $\gamma=0.3$, we then classify the tourism flow from $h$ to $f$ as belonging to category 1 when the income per capita of the individuals that compose that flow is at least $30 \%$ higher than the average of all tourists coming from $h$.

Analogously, in the case of country $g$, we have:

$$
\lambda_{g h}=\frac{Y_{g h}}{Y_{h}}
$$

and

$$
D_{g h}=\left\{\begin{array}{c}
1 \text { if } \lambda_{g h}>1+\gamma \\
2 \text { if } \frac{1}{1+\gamma} \leq \lambda_{g h} \leq 1+\gamma \\
3 \text { if } \lambda_{g h}<\frac{1}{1+\gamma}
\end{array} .\right.
$$

Having classified the flows as belonging to a specific segment, the next step is to determine how to incorporate this dimension in the GSS index. For this purpose, we suggest two alternative methods. The first is realized through a very simple procedure whose first step is to obtain:

$$
L_{f g h}=\left\{\begin{array}{c}
1 \text { if }\left|D_{f h}-D_{g h}\right|=0 \\
1-\xi \text { if }\left|D_{f h}-D_{g h}\right|=1 \\
1-v \text { if }\left|D_{f h}-D_{g h}\right|=2
\end{array}\right.
$$

where $0<\xi$, $v \leq 1$, and $\xi \leq v$. $L_{f g h}$ indicates the difference, in terms of segments related to income levels, between the flows coming from each country $h$ to $f$ and $g$.

The average differential (i.e., considering all source countries) can be obtained as a weighted average of the differential concerning each source country, the weights corresponding to the relative importance of each country $h$ as a source of tourists for $f$ and $g$. Thus, we calculate:

$$
R_{f g}=\sum_{h=1}^{H} L_{f g h} \eta_{f g h}
$$

in which:

$$
\eta_{f g h}=\frac{\theta_{f h}+\theta_{g h}}{2}
$$

With $\sum_{h=1}^{H} \eta_{f g h}=1$.
Having obtained $R_{f g}$, we can now use it to correct the GSS index, calculating:

$$
Z_{f g}=R_{f g} M_{f g} .
$$

In this case, the level of similarity, obtained using $M_{f g}$, will be reduced according to the average differential between $f$ and $g$ with respect to income segments in each market. Obviously, the degree of penalization depends on the values given by the researcher to $\xi$ and $v$. higher values for these parameters imply a stronger penalization (lower value for $R_{f g}$ ) and therefore a larger difference between $Z_{f g}$ and $M_{f g}$.

Finally, the GSS indicator that includes this dimension is expressed as follows:

$$
Z_{f g}^{\prime}=\left(1-X_{f g}^{\prime}\right) Z_{f g}+X_{f g}^{\prime}\left(1-\left|X_{f g}-X_{g f}\right|\right) .
$$

Let us now consider the second approach. In this case, the initial step is to compare directly the per capita income associated with the flows arriving at the two countries $\left(Y_{f h}\right.$ and $\left.Y_{g h}\right)$ :

$$
W_{f g h}=\frac{\operatorname{Min}\left(Y_{f h}, Y_{g h}\right)}{\operatorname{Max}\left(Y_{f h}, Y_{g h}\right)} .
$$

The remaining procedure is similar to that of the first approach. Thus, we calculate:

$$
E_{f g}=\sum_{h=1}^{H} W_{f g h} \eta_{f g h}
$$

and

$$
S_{f g}=R_{f g} M_{f g} .
$$

The index including the two dimensions of structural similarity is obtained as:

$$
S_{f g}^{\prime}=\left(1-X_{f g}^{\prime}\right) S_{f g}+X_{f g}^{\prime}\left(1-\left|X_{f g}-X_{g f}\right|\right) .
$$

Concerning the second approach, the maximum degree of GSS between $f$ and $g$ requires: (1) geographical similarity of the flows directed to $f$ and $g$, (2) $X_{f g}=X_{g f}$, and (3) equality of per capita income of the tourists coming from each of the source countries to $f$ and $g$.

\section{An Overall Index of Geographical Similarity}

As a first step of our analysis, we proposed a GSS index that compared the relative weights of each source country. Then, we extended that index 
to include additional dimensions. Table 1 provides a summary of the indicators previously introduced with the identification of the dimensions captured by each of them.

The purpose of this section is to propose a way to combine in a single indicator $\left(P_{f g}\right)$ all five of the dimensions discussed in this study. To obtain this new measure, we calculate the weighted average of the indicators of structural similarity corrected by the level of overlap between the volumes of tourism flows obtained considering different levels of geographical disaggregation. Thus, the first three dimensions identified above-relative weights of the source countries, volume of tourism flows, and groups of countries-are taken into account. In order to incorporate the remaining two dimensions, the index calculated at the country level (i.e., the most disaggregated level) is obtained according to the second methodology proposed to capture the dimension related to the motivation of the trip and incorporates a penalization depending on the degree of dissimilarity in terms of income, following the second procedure presented in the section on types of tourists.

Thus, we obtain:

$$
P_{f g}=\sum_{j=1}^{J-1} \mu^{j} V_{f g}^{j}+\mu^{J} E_{f g}^{J} O_{f g},
$$

where:

$$
V_{f g}^{j}=M_{f g}^{j}-\frac{1}{\tau}\left(1-\psi_{f g}\right) M_{f g}^{j}
$$

and

$$
E_{f g}^{J}=\sum_{h_{J}=1}^{H_{J}} W_{f g h_{J}} \eta_{f g h_{J}} .
$$

Additionally:

$$
O_{f g}=\alpha_{1} V_{f g}^{J}+\alpha_{2} C_{f g}^{J}
$$

in which:

$$
C_{f g}^{J}=I_{f g}^{J}-\frac{1}{\tau}\left(1-\psi_{f g}\right) I_{f g}^{J}
$$

and

$$
I_{f g}^{J}=1-\frac{1}{2}\left[\sum_{h_{J=1}}^{H_{J}} \sum_{t=1}^{T}\left|\theta_{f_{h_{J} t}}-\theta_{g h_{J t}}\right|\right]
$$

with

$$
\theta_{f_{h} t}=\frac{A_{f h_{J t}}}{\sum_{h_{J=1}}^{H_{J}} \sum_{t=1}^{T} A_{g h J t}}
$$

and

$$
\theta_{g h J t}=\frac{A_{g h_{J} t}}{\sum_{h_{J=1}}^{H_{J}} \sum_{t=1}^{T} A_{g h_{J} t}}
$$

with $\alpha_{1}+\alpha_{2}=1$.

The overall GSS index, which, as noted above, incorporates the five dimensions discussed as being relevant for the purpose of assessing the geographical similarity of the tourism structures arriving at $f$

\begin{tabular}{|c|c|c|c|c|c|}
\hline \multirow[b]{2}{*}{ Index } & \multirow{2}{*}{$\begin{array}{c}\text { Core Dimension } \\
\text { Relative Weight of } \\
\text { the Source Countries }\end{array}$} & \multicolumn{4}{|c|}{ Other Dimensions } \\
\hline & & $\begin{array}{l}\text { Volume of } \\
\text { Tourism }\end{array}$ & $\begin{array}{l}\text { Groups of } \\
\text { Countries }\end{array}$ & $\begin{array}{c}\text { Trip } \\
\text { Motivation }\end{array}$ & $\begin{array}{l}\text { Types of } \\
\text { Tourists }\end{array}$ \\
\hline$M_{f g}^{\prime}$ & $\mathrm{x}$ & & & & \\
\hline$V_{f g}^{\prime}$ & $\mathrm{X}$ & $\mathrm{x}$ & & & \\
\hline$B_{f g}^{\prime}$ & $\mathrm{x}$ & & $\mathrm{x}$ & & \\
\hline$I_{f g}^{\prime}$ and $U_{f g}^{\prime}$ & $\mathrm{x}$ & & & $\mathrm{x}$ & \\
\hline$Z_{f g}^{\prime}$ and $S_{f g}^{\prime}$ & $\mathrm{x}$ & & & & $\mathrm{x}$ \\
\hline$P_{f g}^{\prime}$ & $\mathrm{x}$ & $\mathrm{x}$ & $\mathrm{x}$ & $\mathrm{x}$ & $\mathrm{x}$ \\
\hline
\end{tabular}
and $g$, is obtained as follows:

$$
P_{f g}^{\prime}=\left(1-X_{f g}^{\prime}\right)+P_{f g}+X_{f g}^{\prime}\left(1-\left|X_{f g}-X_{g f}\right|\right) \text {. }
$$

Clearly, the existence of a maximum level of GSS is now more demanding, requiring, simultaneously,

Table 1

Geographical Structural Similarity Indexes 
Table 2

Definition of Regions and Subregions for the Empirical Analysis

\begin{tabular}{|c|c|}
\hline Continents/Regions & Subregions \\
\hline \multicolumn{2}{|l|}{ Africa } \\
\hline \multirow[t]{4}{*}{ Central Africa } & Angola \\
\hline & Cameroon, Central African Republic, Chad \\
\hline & Equatorial Guinea, São Tomé and Príncipe \\
\hline & Congo, Democratic Republic of the Congo, Gabon \\
\hline \multirow[t]{5}{*}{ Eastern Africa } & Burundi, Rwanda, Uganda \\
\hline & Comoros, Madagascar, Mauritius, Reunion, Seychelles \\
\hline & Djibouti, Eritrea, Ethiopia, Kenya, Somalia \\
\hline & Malawi, Mozambique, United Republic of Tanzania \\
\hline & Zambia, Zimbabwe \\
\hline \multirow[t]{4}{*}{ Northern Africa } & Algeria, Libya, Tunisia \\
\hline & Egypt \\
\hline & Morocco \\
\hline & Sudan \\
\hline \multirow[t]{3}{*}{ Southern Africa } & Botswana, Namibia \\
\hline & Lesotho, Swaziland \\
\hline & South Africa \\
\hline \multirow[t]{7}{*}{ Western Africa } & Benin, Burkina Faso, Ghana, Togo \\
\hline & Cape Verde \\
\hline & Cote D’Ivoire, Liberia, Sierra Leone \\
\hline & Guinea, Guinea-Bissau \\
\hline & Mali, Niger \\
\hline & Gambia, Mauritania, Senegal \\
\hline & Nigeria \\
\hline \multicolumn{2}{|l|}{ America } \\
\hline \multirow[t]{5}{*}{ Caribbean } & Cayman Islands, Cuba, Dominican Republic, Haiti, Jamaica, Puerto Rico \\
\hline & Aruba, Bonaire, Curaçao \\
\hline & $\begin{array}{l}\text { Anguilla, Antigua and Barbuda, British Virgin Islands, Guadeloupe, Montserrat, Saba, } \\
\text { Saint Eustatius, Saint Kitts, Saint Maarten, United States Virgin Islands }\end{array}$ \\
\hline & Bahamas, Turks and Caicos Islands \\
\hline & $\begin{array}{l}\text { Barbados, Dominica, Grenada, Martinique, Saint Lucia, Saint Vicent and The Grenadines, } \\
\text { Trinidad and Tobago }\end{array}$ \\
\hline \multirow[t]{2}{*}{ Central America } & Mexico \\
\hline & Belize, Costa Rica, El Salvador, Guatemala, Honduras, Nicaragua, Panama \\
\hline Northern America & Bermuda, Canada, United States \\
\hline \multirow[t]{4}{*}{ South America } & Argentina, Paraguay, Uruguay \\
\hline & Brazil \\
\hline & French Guiana, Guyana, Suriname \\
\hline & Bolivia, Chile, Colombia, Ecuador, Peru, Venezuela \\
\hline \multicolumn{2}{|r|}{ 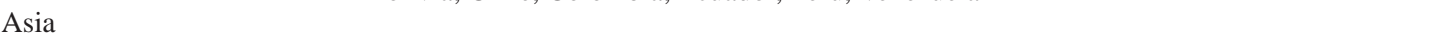 } \\
\hline \multirow[t]{3}{*}{ Central Asia } & Kazakhstan \\
\hline & Kyrgyzstan, Tajikistan \\
\hline & Turkmenistan, Uzbekistan \\
\hline \multirow[t]{3}{*}{ East Asia } & China, Hong Kong, Macao, Mongolia, Taiwan \\
\hline & Japan \\
\hline & Democratic People’s Republic of Korea, Republic of Korea \\
\hline \multirow[t]{4}{*}{ South Asia } & Afghanistan, Pakistan \\
\hline & Bangladesh, Bhutan, India, Nepal, Sri Lanka \\
\hline & Maldives \\
\hline & Myanmar \\
\hline \multirow[t]{4}{*}{ South East Asia } & Cambodia, Vietnam, Lao People’s Democratic Republic \\
\hline & Indonesia, Timor \\
\hline & Philippines, Brunei Darussalam \\
\hline & Thailand, Malaysia, Singapore \\
\hline \multirow[t]{3}{*}{ Western Asia } & Armenia, Georgia, Azerbaijan \\
\hline & Bahrain, United Arab Emirates, Qatar, Kuwait \\
\hline & Islamic Republic of Iran, Iraq \\
\hline
\end{tabular}


Table 2 (Continued)

\begin{tabular}{ll}
\hline Continents/Regions & \\
\hline & Israel, Palestine \\
& Lebanon, Syrian Arab Republic, Jordan \\
& Oman, Yemen \\
& Saudi Arabia \\
Europe & Belarus, Ukraine, Russian Federation \\
Eastern Europe & Czech Republic, Hungary, Poland, Slovakia \\
& Bulgaria, Republic of Moldova, Romania \\
Northern Europe & Estonia, Latvia, Lithuania \\
& Ireland, United Kingdom \\
& Denmark, Finland, Iceland, Norway, Sweden \\
Southern Europe & Cyprus, Greece, Malta, Turkey \\
& Italy, San Marino \\
& Albania, Bosnia and Herzegovina, Croatia, Montenegro, Serbia, Slovenia, The Former \\
& Yugoslav Republic of Macedonia \\
Andorra, Portugal, Spain \\
Bestern Europe & France, Monaco \\
& Austria, Germany, Liechtenstein, Switzerland \\
Pacific & Australia, New Zealand \\
Australia, New Zealand & Fiji, New Caledonia, Papua New Guinea, Solomon Islands, Vanuatu \\
Melanesia & Federated States of Micronesia, Guam, Kiribati, Marshall Islands, Nauru, Northern \\
Micronesia & Mariana Islands, Palau \\
Polynesia & American Samoa, Cook Islands, French Polynesia, Niue, Samoa, Tonga, Tuvalu \\
\hline
\end{tabular}

all the conditions mentioned earlier in the individual analysis of the different dimensions.

\section{Results and Discussion}

In this section, the methodology proposed above is illustrated with data for some important tourism destinations. In this example we use data on inbound and outbound tourism flows provided by the World Tourism Organization for 2009 and consider 222 source countries and 16 destination countries from the five continents:

- Africa: Egypt (EG) and Morocco (MA);

- America: Canada (CA), Cuba (CU), Chile (CL), and the United States (USA);

- Asia: China (CN), Republic of Korea (KR), India (IN), and Israel (IL);

- Europe: Belgium (BE), Italy (IT), Russian Federation (RU), and the United Kingdom (UK);

- Oceania: Australia (AU) and New Zealand (NZ).

In order to calculate the indices that take into account the dimension "groups of countries," we assume three disaggregation levels, including, respectively, five continents, 22 regions, and 73 subregions. To that end, we take as reference the information provided by the United Nations geoscheme. Table 2 shows the composition of these groups of countries.

Regarding the trip motivation, this database provides three alternative motivations: (1) holidays, leisure, and recreation, (2) other personal purposes, and (3) business and professional.

In order to illustrate the measures discussed in the previous section, we obtain 17 indicators, as shown in Table 3.

Because the database does not contain the necessary information to measure $E_{f g}^{J}$, we test the robustness of the results using two alternative values [0.9 in the case of $P_{f g}^{\prime}(1)$ and 0.75 in $\left.P_{f g}^{\prime}(2)\right] .^{2}$ Applying these indicators to the database allows us to rank country pairs according to their degree of GSS. In this example, because 16 countries are analyzed, we obtain 120 bilateral comparisons. In Table 4, the 12 country pairs showing the greatest similarity (top 10\%) are shown.

Three main conclusions can be drawn from Table 4. First, according to all indicators, the highest 
similarity level belongs to one of the following country pairs: Australia-New Zealand or Italy-UK. There are only three indices in which these two pairs do not occupy the first two positions of the ranking [ $V_{f g}^{\prime}(1)$ with Australia-New Zealand appearing in fourth place and $B_{f g}^{\prime}(5)$ and $B_{f g}^{\prime}(6)$ where Italy-UK ranks in third place]. Second, there are also other pairs in which the competition assessed by the geographical structure of the tourism flows is relatively high: Belgium-Italy, Belgium-UK, Canada-US, Belgium-Morocco, Cuba-Israel, and Israel-UK. It is interesting to find that a given overall level of GSS can have different causes, and a remarkable advantage of the approach we propose is that it allows us to track them easily. Let us analyze two cases, starting with the pair Cuba-Israel. In the case of these two countries, we obtain a first measure that compares the weights associated with the relative importance of the different destination countries, $M_{f g}^{\prime}$ with the value of 0.451 . Adding the dimension "volume of tourism" in order to get the index $V_{f g}^{\prime}$ introduces a very small gap between $M_{f g}^{\prime}$ and $V_{f g}^{\prime}$ [e.g., $V_{f g}^{\prime}(1)=0.440$ ], as the volume of tourism captured by these countries is very similar. In addition, there are significant differences in terms of trip motivation, which penalize

Table 3

Geographical Structural Similarity Indices

\begin{tabular}{ll}
\hline Index & \multicolumn{1}{c}{ Parameters } \\
\hline$M_{f g}^{\prime}$ & \\
$V_{f g}^{\prime}(1)$ & $\tau=1$ \\
$V_{f g}^{\prime}(2)$ & $\tau=1.5$ \\
$V_{f g}^{\prime}(3)$ & $\tau=2$ \\
$V_{f g}^{\prime}(4)$ & $\tau=3$ \\
$B_{f g}^{\prime}(1)$ & $\mu_{1}=0.05 ; \mu_{2}=0.05 ; \mu_{3}=0.9$ \\
$B_{f g}^{\prime}(2)$ & $\mu_{1}=0.025 ; \mu_{2}=0.075 ; \mu_{3}=0.9$ \\
$B_{f g}^{\prime}(3)$ & $\mu_{1}=0.125 ; \mu_{2}=0.125 ; \mu_{3}=0.75$ \\
$B_{f g}^{\prime}(4)$ & $\mu_{1}=0.1 ; \mu_{2}=0.15 ; \mu_{3}=0.75$ \\
$B_{f g}^{\prime}(5)$ & $\mu_{1}=0.25 ; \mu_{2}=0.25 ; \mu_{3}=0.5$ \\
$B_{f g}^{\prime}(6)$ & $\mu_{1}=0.2 ; \mu_{2}=0.3 ; \mu_{3}=0.5$ \\
$I_{f g}^{\prime}$ & \\
$U_{f g}^{\prime}(1)$ & $\kappa_{1}=0.9 ; \kappa_{2}=0.1$ \\
$U_{f g}^{\prime}(2)$ & $\kappa_{1}=0.75 ; \kappa_{2}=0.25$ \\
$U_{f g}^{\prime}(3)$ & $\kappa_{1}=0.5 ; \kappa_{2}=0.5$ \\
$P_{f g}^{\prime}(1)$ & $\tau=2 ; \alpha_{1}=0.5 ; \alpha_{2}=0.5 ; \kappa_{1}=0.5 ; \kappa_{2}=0.5 ;$ \\
$P_{f g}^{\prime}(2)$ & $\mu_{1}=0.1 ; \mu_{2}=0.15 ; \mu_{3}=0.75$ \\
& $\mu_{1}=0.1 ; \mu_{2}=0.15 ; \mu_{3}=0.75$ \\
\hline
\end{tabular}

the index [e.g., $\left.U_{f g}^{\prime}(1)=0.274\right]$. However, the flows of tourism that do not come from the same source countries come from countries that are nevertheless geographically close, which greatly increases the degree of GSS, measured by $B_{f g}^{\prime}$. The final indices $P_{f g}^{\prime}$ are a summary of these different influences. A second case is the pair Israel-UK. These countries start with a higher $M_{f g}^{\prime}$ equal to 0.623 and are strongly penalized by differences in the volume of tourism [e.g., $V_{f g}^{\prime}(1)=0.077$ ]. In terms of the dimension "groups of countries," the indicators $B_{f g}^{\prime}$ are close to $M_{f g}^{\prime}$, which can be interpreted as meaning that the source countries that are important for Israel and that are not for the UK and vice versa belong to distant regions.

Third, when multidimensional indices are considered (i.e., all indicators with the exception of $\left.M_{f g}^{\prime}\right)$ there is a considerable effect on the level of similarity, in which the impact is greater in the case of the adjustment by the "volume of tourism" $\left(V_{f g}^{\prime}\right)$ and "groups of countries" $\left(B_{f g}^{\prime}\right)$.

In order to evaluate the consistency of the evidence provided by these indices, we calculate correlation coefficients between these alternative measures (Table 5). Below the diagonal we present the correlation coefficients calculated using the values of the indices, and to obtain the coefficients above the diagonal we started by ranking country pairs according to each measure and then established the correlation between these rankings.

The evidence presented in Table 5 gives us some interesting insights. First, on average, the correlation coefficients between the different indicators are high, with $91 \%$ of the correlation coefficients above 0.8 and $61 \%$ above 0.9 . Second, the adjustment with the greatest influence on the level of structural similarity arises when the dimension "volume of tourism" is introduced into the analysis $\left(V_{f g}^{\prime}\right)$, in particular when full adjustment of the base index to the volume is carried out $(\tau=1)$. In this last case, several coefficients drop below 0.6. Third, the sensibility of $U_{f g}^{\prime}$ and $B_{f g}^{\prime}$ to alternative parameters is lower than in the previous case. Considering $B_{f g}^{\prime}$, the adjustment is higher when we reduce the weight given to more disaggregated levels of geographical separation. Finally, a comparison between the correlation coefficients based on the indices with those obtained from the ranking shows that these coefficients are very similar (the average correlation is 


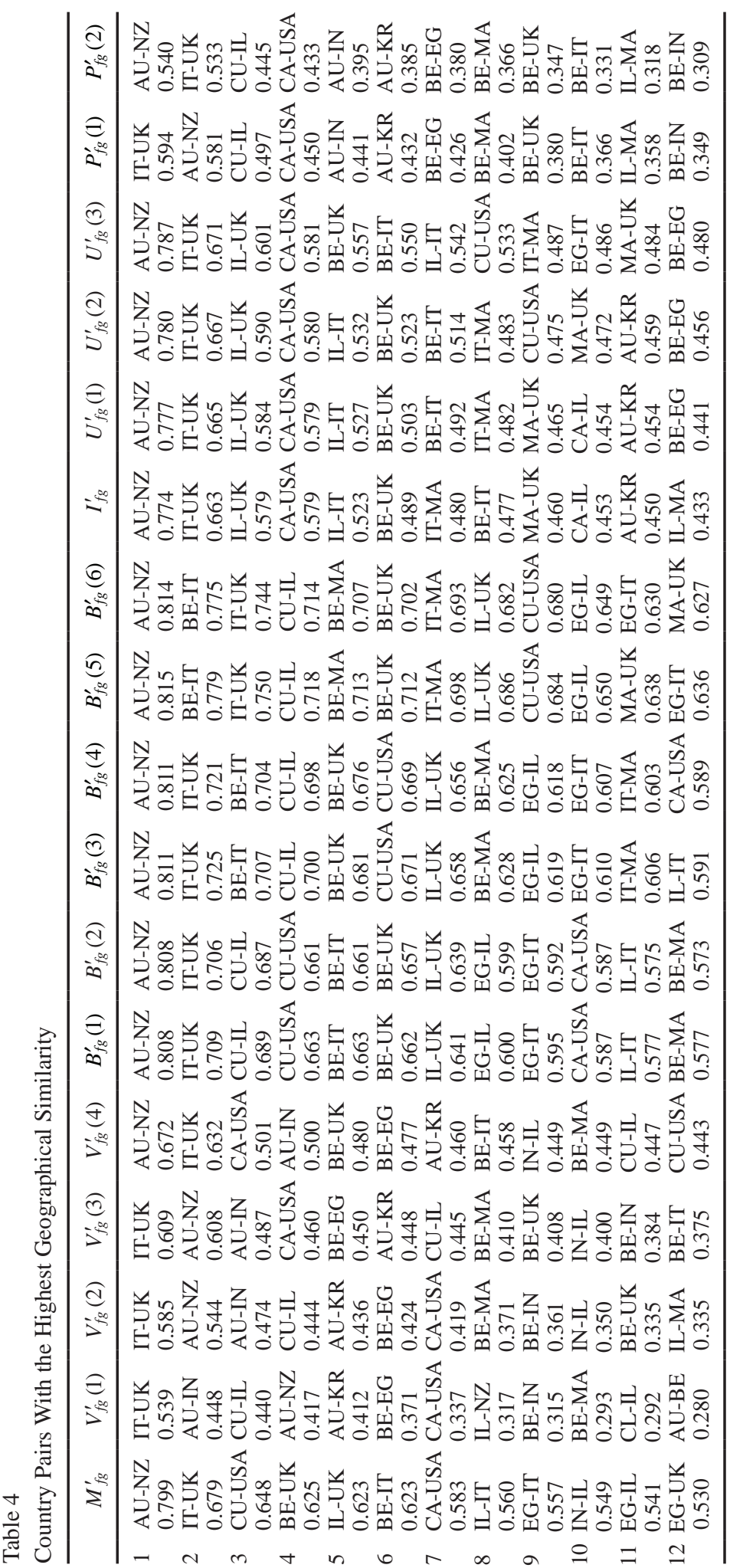


0.892 using the indices and 0.898 when we consider the rankings).

\section{Conclusion}

In a context of tourism globalization and increasing market segmentation, countries actively compete to attract tourism flows. In this study we have proposed a set of indicators to measure an important determinant of the competition between two countries for the attraction of tourism: the degree of geographical structural similarity of the tourism inflows. Beyond the consideration of the relative weight of each source market, we argued that a detailed analysis of the geographical structural similarity implies the consideration of a multidimensional concept, in order to accommodate important elements of the tourism flows today.

Using a sample of 16 countries from the five continents, Australia-New Zealand and Italy-UK emerged as the two country pairs showing the highest degree of similarity. At the methodological level, we found a high correlation between the results produced by the different indicators. Starting with the base index, the most significant change occurs when the adjustment by the "volume of tourism" is introduced.
At the methodological level, three aspects should be emphasized. First, it should be noted that the approach proposed can be extended to include other dimensions considered as relevant, including other forms of market segmentation. Second, the methodology suggested has a high degree of flexibility, in the sense that only the dimensions considered as relevant in each particular analysis are taken into account. In fact, it emerges from the presentation above that it is easy to adapt the measures discussed in order to retain only the relevant dimensions in each specific empirical analysis. Third, the discussion above also makes it clear that the implementation of the methodology involves setting specific values for several parameters. Despite introducing an increased subjectivity, this fact has, in our opinion, the important advantage of implying the explicit assumption of the methodological options assumed by each study, making clear the perspective adopted and the underlying assumptions.

This study sought primarily to propose a methodological contribution to the assessment of the degree of geographical structural similarity between two countries with regard to tourism attraction. The methodology offers valuable inputs for policy action. In fact, the methodology discussed in this study can be seen as a diagnostic tool, providing

Table 5

Correlation Matrix

\begin{tabular}{|c|c|c|c|c|c|c|c|c|c|c|c|c|c|c|c|c|c|}
\hline & $M_{f g}^{\prime}$ & $V_{f g}^{\prime}(1)$ & $V_{f g}^{\prime}$ & $V_{f g}^{\prime}$ & $V_{f g}^{\prime}(4)$ & $B_{f g}^{\prime}(1)$ & $B_{f g}^{\prime}(2)$ & $B_{f g}^{\prime}(3)$ & $B_{f g}^{\prime}(4)$ & $B_{f g}^{\prime}(5)$ & $B_{f g}^{\prime}(6)$ & $I_{f g}^{\prime}$ & $U_{f g}^{\prime}(1)$ & $U_{f g}^{\prime}$ & $U_{f g}^{\prime}(3)$ & $P_{f g}^{\prime}(1)$ & $P_{f g}^{\prime}(2)$ \\
\hline$M_{f g}^{\prime}$ & & 0.615 & 0.885 & 0.945 & 0.979 & 0.980 & 0.982 & 0.960 & 0.964 & 0.911 & 0.921 & 0.932 & 0.951 & 0.971 & 0.988 & 0.917 & 0.913 \\
\hline$V_{f g}^{\prime}(1)$ & 0.595 & & 0.895 & 0.821 & 0.747 & 0.630 & 0.630 & 0.610 & 0.610 & 0.571 & 0.577 & 0.547 & 0.563 & 0.579 & 0.596 & 0.813 & 0.808 \\
\hline$V_{f g}^{\prime}(2)$ & 0.852 & 0.927 & & 0.986 & 0.957 & 0.885 & 0.886 & 0.863 & 0.865 & 0.815 & 0.823 & 0.808 & 0.828 & 0.848 & 0.868 & 0.967 & 0.962 \\
\hline$V_{f g}^{\prime}(3)$ & 0.929 & 0.850 & 0.985 & & 0.990 & 0.940 & 0.941 & 0.920 & 0.922 & 0.871 & 0.880 & 0.871 & 0.891 & 0.911 & 0.930 & 0.978 & 0.973 \\
\hline$V_{f g}^{\prime}(4)$ & 0.974 & 0.762 & 0.949 & 0.989 & & 0.970 & 0.971 & 0.949 & 0.953 & 0.901 & 0.911 & 0.907 & 0.926 & 0.946 & 0.965 & 0.968 & 0.963 \\
\hline$B_{f g}^{\prime}(1)$ & 0.980 & 0.612 & 0.854 & 0.924 & 0.963 & & 1.000 & 0.992 & 0.994 & 0.960 & 0.967 & 0.897 & 0.918 & 0.941 & 0.961 & 0.942 & 0.941 \\
\hline$B_{f g}^{\prime}(2)$ & 0.981 & 0.612 & 0.855 & 0.925 & 0.964 & 1.000 & & 0.990 & 0.993 & 0.955 & 0.963 & 0.900 & 0.921 & 0.943 & 0.964 & 0.941 & 0.940 \\
\hline$B_{f g}^{\prime}(3)$ & 0.967 & 0.600 & 0.840 & 0.910 & 0.949 & 0.996 & 0.994 & & 1.000 & 0.986 & 0.990 & 0.872 & 0.894 & 0.919 & 0.941 & 0.940 & 0.942 \\
\hline$B_{f g}^{\prime}(4)$ & 0.970 & 0.601 & 0.842 & 0.912 & 0.951 & 0.997 & 0.996 & 1.000 & & 0.982 & 0.987 & 0.877 & 0.899 & 0.923 & 0.945 & 0.939 & 0.940 \\
\hline$B_{f g}^{\prime}(5)$ & 0.930 & 0.570 & 0.804 & 0.872 & 0.911 & 0.972 & 0.968 & 0.989 & 0.987 & & 0.999 & 0.817 & 0.840 & 0.866 & 0.890 & 0.915 & 0.920 \\
\hline$B_{f g}^{\prime \prime}(6)$ & 0.939 & 0.573 & 0.810 & 0.879 & 0.919 & 0.978 & 0.975 & 0.993 & 0.991 & 0.999 & & 0.828 & 0.851 & 0.876 & 0.910 & 0.920 & 0.924 \\
\hline$I_{f g}^{\prime}$ & 0.924 & 0.564 & 0.797 & 0.865 & 0.904 & 0.881 & 0.883 & 0.862 & 0.865 & 0.817 & 0.826 & & 0.997 & 0.990 & 0.973 & 0.860 & 0.856 \\
\hline$U_{f g}^{\prime}(1)$ & 0.940 & 0.572 & 0.809 & 0.879 & 0.919 & 0.899 & 0.901 & 0.880 & 0.884 & 0.836 & 0.846 & 0.999 & & 0.996 & 0.985 & 0.877 & 0.873 \\
\hline$U_{f g}^{\prime}(2)$ & 0.960 & 0.581 & 0.825 & 0.897 & 0.938 & 0.922 & 0.925 & 0.905 & 0.908 & 0.861 & 0.871 & 0.994 & 0.998 & & 0.995 & 0.895 & 0.891 \\
\hline$U_{f g}^{\prime}(3)$ & 0.984 & 0.592 & 0.843 & 0.917 & 0.960 & 0.952 & 0.954 & 0.936 & 0.939 & 0.895 & 0.904 & 0.978 & 0.986 & 0.995 & & 0.910 & 0.906 \\
\hline$P_{f g}^{\prime}(1)$ & 0.895 & 0.856 & 0.974 & 0.981 & 0.963 & 0.920 & 0.919 & 0.918 & 0.918 & 0.898 & 0.902 & 0.851 & 0.862 & 0.877 & 0.892 & & 0.999 \\
\hline$P_{f g}^{\prime}(2)$ & 0.894 & 0.850 & 0.969 & 0.977 & 0.960 & 0.919 & 0.918 & 0.918 & 0.918 & 0.901 & 0.904 & 0.851 & 0.862 & 0.876 & 0.891 & 0.999 & \\
\hline
\end{tabular}


important information that can be used for defining more adequate measures to successfully compete in the international arena to attract a greater volume of tourism flows. The several measures suggested herein provide detailed support not only regarding the identification of the actual and potential competitors, but also, and no less important, of the causes behind the level of competition identified. This evidence supports concrete actions devoted, for example, to reinforcing the marketing strategy for some market segments (in terms of per capita income or geographical area, for instance) or to consolidating the strategy of product differentiation.

Of course, a correct diagnostic tool requires reliable data. This is an area that still demands considerable effort because the statistical data available is still far from complete in some important dimensions. Therefore, the production of new and better data on tourism flows and their characterization elements is another critical priority in order to allow better diagnoses and, as a final step, better policies.

Two final messages should be taken away. First, a critical implication of the present article is that competition in terms of tourism attraction could have very different sources, requiring different forms of intervention, as a result. Second, it should be noted that the suggested methodology and the resulting measures can be included, along with multiple other factors that influence the tourism competitiveness of the countries in a broader framework of analysis to assess the competition between two countries regarding their capacity to attract tourism flows.

\section{Notes}

${ }^{1}$ Some studies that analyze the effects on economic growth of an increase in tourism by exploring the consequences on the allocation of labor and capital between sectors and on prices of tradable and nontradable goods (and consequently on terms of trade) find that the long-term effects might be smaller than short-term effects, and that under some circumstances, inequalities in income distribution may ultimately be aggravated (see Chao, Hazari, Laffargue, Sgro, \& Yu, 2006; Copeland, 1991). Many articles following this line of research argue that there is a relevant role for public policy implementing measures to: promote income redistribution between high and low income households and protect the poor; foster innovation; promote investment in education; provide guidance to private initiatives in order to increase their efficiency; preserve natural resources that are at the core of the tourism industry; and develop the transport infrastructure (Blake, Arbache, Sinclair, \& Teles, 2008; Capó, Font, \& Nadal, 2007; Dwyer et al., 2006; Wattanakuljarus \& Coxhead, 2008).

${ }^{2}$ It is important to remember that these values express the differences, in average terms, of the per capita incomes associated with the tourism flows that go from the group of countries $h$ to $f$ and $g$. A higher value (closer to 1 ) indicates a small difference, therefore reinforcing the competition between the two destination countries regarding the geographical structure of their tourism inflows. However, as our purpose is essentially an illustrative one, we test the sensibility of the conclusion assuming a smaller but still moderate value (0.75). Applied studies could, of course, test additional alternative values for this parameter, enriching the understanding of its impact over the entire range of admissible values.

\section{References}

Blake, A., Arbache, J., Sinclair, M., \& Teles, V. (2008). Tourism and poverty relief. Annals of Tourism Research, 35, 107-126.

Bloom, J. (2004). Tourist market segmentation with linear and non-linear techniques. Tourism Management, 25, 723-733.

Bristow, G. (2005). Everyone’s a "winner": Problematising the discourse of regional competitiveness. Journal of Economic Geography, 5, 285-304.

Capó, J., Font, A., \& Nadal, J. (2007). Dutch disease in tourism economies: Evidence from the Balearics and the Canary Islands. Journal of Sustainable Tourism, 15, 615-627.

Chao, C., Hazari, B., Laffargue, J., Sgro, P., \& Yu, E. (2006). Tourism, Dutch disease and welfare in an open dynamic economy. Japanese Economic Review, 57, 501-515.

Chen, J. (2003). Market segmentation by tourists' sentiments. Annals of Tourism Research, 30, 178-193.

Copeland, B. (1991). Tourism, welfare and de-industrialization in a small open economy. Economica, 58, 515-529.

Cracolici, M., \& Nijkamp, P. (2009). The attractiveness and competitiveness of tourist destination: A study of Southern Italian regions. Tourism Management, 30, 336-344.

Crespo, N., \& Fontoura, M. (2007). Integration of CEECs into EU market: Structural change and convergence. Journal of Common Market Studies, 45, 611-632.

Crespo, N., \& Simões, N. (2012). On the measurement of a multidimensional concept of structural similarity. Economic Letters, 116, 115-117.

Crouch, G. (2007). Modelling destination competitiveness: A survey and analysis of the impact of competitiveness attributes. Queensland, Australia: CRC for Sustainable Tourism.

Crouch, G., \& Ritchie, J. R. B. (1999). Tourism, competitiveness, and societal prosperity. Journal of Business Research, 44, 137-152.

De Benedictis, L., \& Tajoli, L. (2007). Economic integration and similarity in trade structures. Empirica, 34, 117-137.

Dumitrescu, L., \& Vinerean, S. (2010). International tourism market segmentation based on consumer behavior. 
Review of International Comparative Management, 11, 757-763.

Dwyer, L., \& Forsyth, P. (2010). Methods of estimating destination price competitiveness: A case of horses for courses? Current Issues Tourism, 14, 751-777.

Dwyer, L., Forsyth, P., Fredline, L., Jago, L., Deery, M., \& Lundie, S. (2006). Concepts of tourism yield and their measurement. Queensland, Australia: CRC for Sustainable Tourism.

Dwyer, L., Forsyth, P., \& Rao, P. (2000). The price competitiveness of travel and tourism: A comparison of 19 destinations. Tourism Management, 21, 9-22.

Dwyer, L., Forsyth, P., \& Rao, P. (2002). Destination price competitiveness: Exchange rate changes versus inflation rates. Journal of Travel Research, 40, 328-336.

Dwyer, L., \& Kim, C. (2003). Destination competitiveness: Determinants and indicators. Current Issues in Tourism, 6, 369-414.

Dwyer, L., Mellor, R., Livaic, Z., Edwards, D., \& Kim, C. (2004). Attributes of destination competitiveness: A factor analysis. Tourism Analysis, 9, 91-101.

Enright, M., \& Newton, J. (2004). Tourism destination competitiveness: A quantitative approach. Tourism Management, 25, 777-788.

Enright, M., \& Newton, J. (2005). Determinants of tourism destination competitiveness in Asia Pacific: Comprehensiveness and universality. Journal of Travel Research, 43, 339-350.

European Commission. (2007). Agenda for a sustainable and competitive European tourism (COM (2007) 621 final). Brussels, Belgium: Author.

Gomezelj, D., \& Mihalic, T. (2008). Destination competitiveness-applying different models, the case of Slovenia. Tourism Management, 29, 294-307.

Hall, C. (2007). Tourism and regional competitiveness. In J. Tribe \& D. Airey (Eds.), Developments in tourism research (pp. 217-230). Oxford, UK: Elsevier.

Jenkins, R. (2008). Measuring the competitive threat from China for other Southern exporters. World Economy, 31, 1351-1366.

Kim, C., \& Dwyer, L. (2003). Destination competitiveness and bilateral tourism flows between Australia and Korea. Journal of Tourism Studies, 14, 55-67.

Kirovska, Z. (2011). Strategic management within the tourism and the world globalization. UTMD Journal of Economics, 2, 69-76.

Kozak, M. (2002). Measuring competitive destination performance: A study of Spain and Turkey. Journal of Travel and Tourism Marketing, 13, 83-110.

Kulendran, N., \& Dwyer, L. (2009). Measuring the return from Australian tourism marketing expenditure. Journal of Travel Research, 47, 275-284.

Lusticky, M. (2011) Benchmarking as a quality enhancement method of regional planning in tourism. Journal of Global Management, 2, 1-12.
Mazanec, J., \& Ring, A. (2011). Tourism destination competitiveness: Second thoughts on the World Economic Forum Reports. Tourism Economics, 17, 725-751.

Mazanec, J., Wöber, K., \& Zins, A. (2007). Tourism destination competitiveness: From definition to explanation? Journal of Travel Research, 46, 86-95.

McKercher, B., Chan, A., \& Lam, C. (2008). The impact of distance on international tourist movements. Journal of Travel Research, 47, 208-224.

McKercher, B., \& Lew, A. (2003). Distance decay and the impact of effective tourism exclusion zones on international travel flows. Journal of Travel Research, 42, 159-165.

Palan, N. (2010). Measurement of specialization — the choice of indices (FIW Working Paper No. 62/2010). Vienna, Austria: Research Centre International Economics.

Palan, N., \& Schmiedeberg, C. (2010). Structural convergence of European countries. Structural Change and Economic Dynamics, 21, 5-100.

Papatheodorou, A. (2001). Why people travel to different places? Annals of Tourism Research, 28, 164-179.

Ritchie, J. R. B., \& Crouch, G. (2000). The competitive destination: A sustainability perspective. Tourism Management, 21, 1-7.

Ritchie, J. R. B., \& Crouch, G. (2003). The competitive destination: a sustainable tourism perspective. Wallingford, UK: CABI Publishing.

Sinclair, M. T. (1998). Tourism and economic development: A survey. Journal of Development Studies, 34, 1-51.

Song, H., Dwyer, L., Li, G., \& Cao, Z. (2012). Tourism economics research: A review and assessment. Annals of Tourism Research, 39(3), 1653-1682.

Squalli, J., Wilson, K., \& Hugo, S. (2008). An analysis of growth competitiveness. International Review of Applied Economics, 22, 115-126.

United Nations Development Programme. (2011). Human development report. New York: Palgrave Macmillan.

Wattanakuljarus, A., \& Coxhead, I. (2008). Is tourism-based development good for the poor? A general equilibrium analysis for Thailand. Journal of Policy Modeling, 30, 929-955.

World Economic Forum. (2013). The travel \& tourism competitiveness report 2013-reducing barriers to economic growth and job creation. Geneva, Switzerland: Author.

Zhang, H. Q., Gu, C., Gu, L., \& Zhang, Y. (2011). The evaluation of tourism destination competitiveness by TOPSIS \& Information Entropy-A case in the Yangtze River Delta of China. Tourism Management, 32, 443-445.

Zhang, H. Q., Kulendran, N., \& Song, H. (2010). Measuring returns on Hong Kong's tourism marketing expenditure. Tourism Economics, 16, 853-865. 